\title{
Üniversite Öğrencilerinin Periyodik Tablo ile İlişkili Bilişsel Yapılarının İncelenmesi*
}

\section{Lütfiye VAROĞLU**, Şenol ŞEN***, Ayhan YILMAZ****}

Öz: Öğrenme sürecinde bireylerin bilgileri nasıl yapılandırdıkları araştırmacılar tarafından ilgi duyulan konulardan bir tanesidir. Yapılan pek çok araştırmada, bireylerin bilişsel yapıları incelenerek, sahip oldukları kavramlar arasındaki bağların ve ilişkilerin ortaya çıkarılması amaçlanmıştır. $\mathrm{Bu}$ sebeple bu çalışmanın amacı, kimyanın temel konularından biri olan periyodik tablo ile ilgili üniversite öğrencilerinin bilişsel yapılarının ortaya çıkarılmasıdır. Çalışmada; bilişsel yapılar, kelime ilişkilendirme testi aracılığıyla incelenmiştir. Çalışmaya bir vakıf üniversitesindeki 2018-2019 akademik yılı bahar döneminde birinci sınıfa devam eden 123 üniversite öğrencisi katılmıştır. Araştırmacılar tarafından, periyodik tablo konusuna ilişkin olarak hazırlanmış kelime ilişkilendirme testi, veri toplama aracı olarak kullanılmıştır. Üniversite öğrencilerinin periyodik tablo konusu ile ilgili bilişsel yapılarını incelemek için; periyot, grup, atom numarası, kütle numarası, ana grup ve geçiş metalleri anahtar kelimelerini içeren kelime ilişkilendirme testi öğrencilere verilmiş ve elde edilen verilerin analizinde ise içerik analizi kullanılmıştır. Frekans tablosu; öğrencilerin, kelime ilişkilendirme testindeki her bir anahtar kelimeye verdikleri yanıtlar değerlendirilerek hazırlanmış ve kesme yöntemi kullanılarak bilişsel yapıları incelenmiştir. Çalışma sonucunda, üniversite öğrencilerinin temel kimyanın önemli konularından biri olan periyodik tablo ile ilgili bilişsel yapıları ortaya çıkarılmıştır.

Anahtar Kelimeler: Bilişsel yapı, Kelime ilişkilendirme testi, Periyodik tablo, Üniversite öğrencileri

\footnotetext{
${ }^{*}$ Bu çalışmanın bir kısmı 6. Ulusal Kimya Eğitimi Kongresi’nde (UKEK 2019) sözlü bildiri olarak sunulmuştur.

** Doktora Öğrencisi, Lefke Avrupa Üniversitesi, Mühendislik Fakültesi, Email:lvaroglu@eul.edu.tr Orcid No: 0000-00032595-5746.

*** Doç. Dr., Hacettepe Üniversitesi, Eğitim Fakültesi, Matematik ve Fen Bilimleri Eğitimi Bölümü, Kimya Eğitimi Anabilim Dal1, Email:schenolschen@gmail.com Orcid No: 0000-0003-3831-3953.
**** Prof. Dr., Hacettepe Üniversitesi, Eğitim Fakültesi, Matematik ve Fen Bilimleri Eğitimi Bölümü, Kimya Eğitimi Anabilim Dal1, Email:ayhany@hacettepe.edu.tr Orcid No: 0000-0003-4252-5510.




\section{Examining of Undergraduate Students' Cognitive Structures related to the Periodic}

Table

Abstract: The way how knowledge is structured in the learning process by individuals is one of the important topics for researchers. In many studies, it is aimed to reveal the connections and relations between concepts of individuals by examining their cognitive structures. For this reason, the aim of the study was to reveal the cognitive structures of undergraduate students related to the periodic table which is one of the essential topics for chemistry. The study was carried out in a foundation university with 123 first year undergraduate students in the spring term of 2018-2019 academic year. The word association test that prepared by the researchers about the periodic table was used as a data collection tool. In an attempt to investigate cognitive structures, the stimulus words such as; period, group, atomic number, mass number, main groups and transition groups were given in the test. Content analysis was used to analyze the data. The frequency table was prepared by evaluating the responses of each keyword in the word association test and the cognitive structures were examined by using the cut-off point technique. As a result of the study, the cognitive structures related to the periodic table, which is one of the important subjects of general chemistry, have been revealed.

Keywords: Cognitive structures, Periodic table, Undergraduate students, Word association test

\section{Giriş}

Öğrenciler, kimyanın bazı konularının soyut olmasından dolayı kimya konularını ve kavramlarını öğrenmede ve kavramsal düzeyde anlamada problemler yaşamaktadırlar. Çünkü birçok soyut kavramı içeren kompleks kimya konularının anlaşılması için öğrencilerin tutarlı bilgi yapıları geliştirmeleri ve birbiriyle ilişkili kavramları anlamaları gerekmektedir (Burrows \& Mooring, 2015). Eğitim alanında yapılan çalışmalar incelendiğinde üniversite öğrencilerinin; kimyasal değişim, kimyasal denge, çözünürlük, periyodik sistem, molekül yapıları, entropi, asitler ve bazlar gibi kimya konularını anlayışları ve bu konulardaki kavram yanılgılarını inceleyen birçok çalışmaya rastlanmaktadır (Abraham, Williamson \& Westbrook, 1994; Barak \& Dori, 2005; Bilgin, Aktaş, Tatar, \& Tüysüz, 2016; Bradley \& Mosimege, 1998; Carson \& Watson, 2002; Geçgel \& Şekerci, 2018; Jenkins \& Shoopman, 2019; Karslı \& Ayas, 2017; Stavy, 1991; Nakhleh, 1992; Özmen, 2004; Pikoli, 2020). Örneğin, Geçgel ve Şekerci (2018) tarafından yürütülen bir çalışmada; öğrencilerin, madde ve özellikleri, fiziksel ve kimyasal 
değişimler, elementler, metaller, bileşikler, 1sı ve sıcaklık, çözeltiler ve koligatif özellikler, asitler ve bazlar, kimyasal bağlar gibi konularda çeşitli alternatif kavramlara sahip oldukları ifade edilmiştir. Benzer şekilde, Karslı ve Ayas (2017) öğrencilerin buharlaşma ve kaynama kavramlarına ilişkin alternatif kavramlara sahip olduklarını tespit etmişlerdir. Aydın (2008) ortaöğretim kimya dersi öğretim programında yer alan periyodik sistem ile ilgili kavramları, kimya içerik standartları ile karşılaştırarak incelemiştir. Bu bağlamda kimya konularına temel oluşturan nitelikteki periyodik tablo konusu ile ilişkili de literatürde çeşitli ulusal ve uluslararası çalışmalar bulunmaktadır (Aydın, 2008; Bayir, 2014; Demircioğlu, Demircioğlu, \& Çalik 2009; Franco-Mariscal, Oliva-Martínez, \& Almoraima Gil, 2014; Schmidt, Baumgärtner, \& Eybe, 2003). Schmidt, Baumgartner ve Eybe (2003) periyodik tablo konusunun kimya derslerinde öğretilen en önemli konulardan biri olduğunu vurgulayarak, izotop ve allotrop gibi kavramlarının periyodik tablo ile zor ilişkilendirilmesinden dolayı öğrenciler tarafından bu terimlerin anlaşılmasının da güçleştiğini belirtmektedirler. Bu nedenle, kimya eğitimi alanında yapılan çalışmalarda farklı öğretim etkinliklerinin periyodik tablo ile ilişkilendirilerek öğrencilere sunulduğu ve böylece kimyanın temel kavramlarının daha iyi anlaşılmasının hedeflendiği görülmektedir (Bayir, 2014; Franco-Mariscal ve diğ., 2014).

Periyodik tablo kimya bilimine önemli bir katkı sağlayan bir model olup, elementlerin yeri, yapısı ve niteliği ile ilgili bilgiler yansıtmaktadır (Ben-Zvi \& Genut, 1998). Periyodik tablo, çizilebilir ve görülebilir olmasına karşın, ifade ettiği bilgilerin büyük bir bölümü soyut yapıdadır (Azizoğlu, Aslan, \& Pekcan, 2015). Periyodik tablo, kimya konularına temel oluşturması açısından kimya eğitimcileri için önem taşımaktadır. Bundan dolayı öğrencilerin periyodik tablo ile ilişkili kavramları zihinlerinde nasıl yapılandırdıklarını ve kavramlar arasında kurmuş oldukları ilişkileri görmek için bilişsel yapılarının belirlenmesi öğrenme sürecindeki problemleri tespit etmek için faydalı olacaktır.

Bilişsel yapı, öğrencilerin uzun süreli hafızalarındaki kavramsal ilişkileri temsil eden kuramsal yapılardır (Shavelson, 1974). Öğretim sürecinde, öğrencilerin bilişsel yapılarının incelenmesi/belirlenmesi öğrenme çıktılarına katkı sağlayacak ve öğretim stratejilerinin geliştirilmesinde etkili olacaktır (Tsai \& Huang, 2002). Tsai ve Huang (2002) öğrenenlerin bilgiyi nasıl elde ettikleri ve yapılandırdıklarını anlamak için bilişsel yapıların belirlenmesinin fen eğitimi araştırmacıları için önemli olduğunu vurgulamaktadırlar. Bilişsel yapıların belirlenmesi; eğitimcilere kavram yanılgılarının ve öğrenme güçlüklerinin tespit edilmesinde ve öğrenme süreçlerinin iyileştirilmesinde yardımcı olmaktadır (Jonassen, 1987). Bilişsel 
yapıların belirlenmesi amacıyla kelime ilişkilendirme testi, kavram haritaları, tanılayıcı dallanmış ağaç ve yapılandırılmış grid gibi teknikler kullanılabilmektedir (Bahar, 2003). Alternatif ölçme değerlendirme tekniklerinden biri olan kelime ilişkilendirme testleri, öğrencilerin bilişsel yapılarını ortaya çıkarmada ve konuyla ilgili kavramlar arasındaki ilişkileri incelemede kullanılabilecek olan etkili bir yöntemdir (Iş̧1kl1, Taşdere, \& Göz, 2011). Nakiboğlu (2008) geleneksel ölçme ve değerlendirme tekniklerinin öğrencilerin bilişsel yapılarını yansıtmada yeterli olmadığını, kelime ilişkilendirme testlerinin ise hem bilişsel yapıları ortaya çıkarmada hem de öğrencilerin kavramsal değişimini tespit etmede kullanışlı bir teknik olduğunu ifade etmiştir.

Kelime ilişkilendirme testleri, öğretim öncesinde öğrencilerin ön bilgi ve hazırbulunuşluk seviyelerini ortaya çıkarmak için tanı amaçlı kullanılabildikleri gibi öğretim sonrasında kavramsal değişimi ve gelişimi takip etmek için teşhis amaçlı da kullanılabilmektedir (Bahar, Johnstone, \& Sutcliffe, 1999; Hastürk, 2017). Literatür incelendiği zaman, kelime ilişkilendirme testlerinin; öğrencilerin bilişsel yapılarının ortaya çıkarılması (Bahar ve diğ., 1999; Ercan, Taşdere, \& Ercan, 2010; Shavelson, 1972; Şen, Varoğlu, \& Yılmaz, 2019a; 2019b), kavram yanılgılarının saptanması (Yücel \& Özkan, 2015) ve kavramsal değişimin tespit edilmesi (Çelikkaya \& Kürümlüoğlu, 2019; Hovardas \& Korfiatis, 2006) gibi farklı amaçlarda kullanıldığg çalışmalara rastlanmaktadır. Kelime ilişkilendirme testleri farklı eğitim ortamlarında kullanılabilme esnekliğine sahip olmaları açısından fen, matematik veya sosyal bilimler gibi farklı disiplinlerdeki çalışmalarda kullanılabilmektedir (Ercan ve diğ., 2010).

Ulusal ve uluslararası literatürde yapılan birçok çalışmada da kelime ilişkilendirme testlerinin öğrencilerin bilişsel yapılarını ortaya çıkarmak için kullanıldığı görülmektedir (Bahar ve diğ., 1999; Balbağ, 2018; Cachapuz \& Maskill, 1987; Gunstone, 1980; Johnstone \& Moynihan, 1985; Sadoglu \& Durukhan, 2017; Shavelson, 1973; Şen ve diğ., 2019a; 2019b). Bahar ve Özatlı (2003) kelime ilişkilendirme testlerinin hazırlanmasının kolay ve kısa zaman diliminde uygulanabilirlikleri açısından kullanışı ılduğunu, ayrıca hem teşhis amacı ile hem de kavramsal değişim stratejisi olarak kullanılabileceklerini belirtmektedirler. Öğrencilerin bilişsel yapılarını ortaya çıkarmak ve bu yapılardaki kavramlar arasındaki ilişkileri ve bağları tespit etmek, uzun süreli belleklerindeki kavramlar arası ilişkilerin yeterliliklerini veya anlamlılık düzeylerinin belirlenmesine yardımcı olmaktadır. Kelime ilişkilendirme testleri ile öğrenciler, yaş grubuna göre genellikle 30-50 saniyelik bir süre zarfında herhangi bir konu ile 
ilişkili olarak verilmiş bir anahtar kavramın çağrıştırdığı sözcükleri yanıt olarak yazarlar. Bahar ve diğerleri (1999) kelime ilişkilendirme testlerinin analizinde, anahtar kelimelere karşın verilen yanıt kelimelerin kaç defa tekrar edildiğini gösteren frekans tablosundan yararlanılarak, öğrencilerin bilişsel yapılarını ortaya çıkaran kavram haritalarını oluşturmak için kesme noktası tekniğini önermektedirler. Kelime ilişkilendirme testleri, öğrencilerin kavramlar arasında oluşturduğu ilişkileri/bağları belirlemek için tasarlanan ve bu amaçla kullanılan bir tekniktir.

Öğrenme sürecinde, bilgilerin bireyler tarafından nasıl yapılandırıldığının ortaya çıkarılması amacıyla bilişsel yapılarının incelenmesi araştırmacılara çeşitli bilgiler sağlayacaktır. Literatürde bilişsel yapıların ortaya çıkarılmasında sıklıkla kullanılan yöntemlerden biri de kelime ilişkilendirme testleridir. Bu noktadan yola çıkılarak, bu çalışmanın amacı üniversite öğrencilerinin periyodik tablo ile ilişkili zihinlerinde neyi birleştirdikleri ve ilişkilendirdiklerini belirlemektir. Çalışma sonucunda elde edilen sonuçların hem öğrenme ortamlarının düzenlenmesinde hem de alınacak önlemler hakkında önemli ipuçları sunacağı düşünülmektedir. Çalışmanın bu amacı doğrultusunda aşağıdaki soruya yanıt aranmıştır.

\section{Problem Cümlesi}

Periyodik tablo konusuyla ilişkili öğrencilerin bilişsel yapıları nasıldır?

\section{Yöntem}

\section{Araştırmanın Modeli}

Bu çalışma nitel araştırma yöntemlerinden biri olan durum çalışması (case study) ile yürütülmüştür. Durum çalışması, araştırılan konunun gerçek bağlamı içerisinde detaylı bir şekilde incelenmesine olanak veren nitel araştırma yöntemlerinden biridir (Patton, 1990; Yıldırım \& Şimşek, 2011).

\section{Katılımcilar}

Çalışmaya, 2018-2019 akademik yılının bahar döneminde, bir vakıf üniversitesinin mühendislik fakültesine devam eden ve genel kimya dersini alan 123 lisans birinci sınıf öğrencisi katılmıştır. Genel kimyanın konularından biri olan periyodik tablo konusunda öğrencilerin bilişsel yapılarını belirlemek için veriler, dersin öğretim elemanı tarafından konu işlendikten sonra toplanmıştır. Tüm katılımcılar çalışmada gönüllü olarak yer almışlardır.

\section{Verilerin Toplanması}

Çalışmanın araştırma konusu üniversite genel kimya dersinin temel konularından biri olan "Periyodik Tablo" olarak belirlenmiştir. Öğrencilerin bilişsel yapılarını ortaya çıkarmak 
amacıyla periyot, grup, atom numarası, kütle numarası, ana grup ve geçiş metalleri anahtar kelimelerinden oluşan kelime ilişkilendirme testleri kullanılmıştır. Seçilen anahtar kelimelerin, periyodik tablo konusunun temel kavramları olduğu ve konu için önem arz ettiği düşünülmüştür. Anahtar kelimeleri seçme aşamasında periyodik tablo ile ilgili ders kazanımları da dikkate alınmıştır. Ayrıca, anahtar kelimelerin seçiminde kimya eğitimi alanında görevli iki öğretim üyesinin görüşü de alınmıştır.

Öğrencilerin, çalışmanın veri toplama aracı olarak kullanılan kelime ilişkilendirme testlerine yönelik bilgi sahibi olmadıkları düşünülerek veriler toplanmadan önce öğrencilere kelime ilişkilendirme testleri ile ilgili bilgiler verilmiştir. Bilgilendirme sonrasında, öğrencilere aşağıda bir kısmı belirtilen düzende anahtar kavramlar bir sayfa A4 kağıt üzerinde verilmiştir. Uygulamada, her bir kavram için 30 saniye süre verilmiştir.

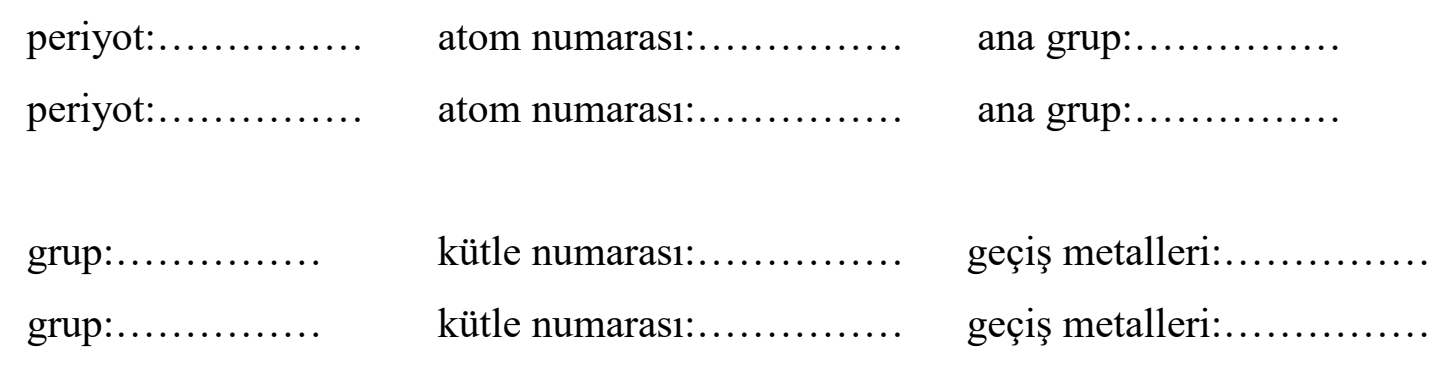

\section{Verilerin Analizi}

Kelime ilişkilendirme testindeki anahtar kavramlara öğrencilerin verdikleri yanıtlar içerik analizi ile incelenerek frekans tablosu hazırlanmıştır. Bahar ve diğerleri (1999) tarafından frekans değerleri baz alınarak kesme noktası tekniğiyle kavram ağı oluşturularak, öğrencilerin konu ile ilgili bilişsel yapılarının ortaya çıkarabileceği belirtilmiştir. Bu noktadan hareketle bu çalışmada frekans değerleri dikkate alınarak kavram ağları hazırlanmıştır. Frekans değerleri en yüksek frekans değerinden en düşük frekans değerine doğru gruplandırılarak, her bir anahtar kavram için en fazla verilen cevap kelimenin belli sayıda aşağısı belirlenerek kesme noktaları tespit edilmiş ve bu frekansın üstünde bulunan cevaplar kavram ağının ilk kısmı olacak şekilde kullanılmıştır. Sonraki kavram ağları için tüm cevap kelimeler kavram ağlarında ifade edilinceye kadar kesme noktası belli aralıklarla aşağıya çekilmiştir. Kesme noktaları aracılığı ile ortaya çıkan kavram ağları, ilgili kesme noktası aralığındaki kavramların öğrenciler tarafından ne kadar tekrar edildiğini ifade etmektedir (Bahar \& Özatlı, 2003; Bahar ve diğ., 1999; Işıklı ve diğ., 2011). Kavram ağları için; (1) kesme noktası 25-35, (2) kesme noktası 1524, (3) kesme noktası 5-14 ve (4) kesme noktası 1-4 olacak şekilde dört kesme noktası belirlenmiştir. 


\section{Bulgular}

Çalışmanın araştırma problemine ilişkin olarak, kelime ilişkilendirme testi yardımıyla öğrencilerin anahtar kelimelere verdikleri yanıt kelimeler ve bu yanıtların frekans değerlerinden yola çıkılarak bilişsel yapıların incelenmesi için Bahar ve diğerleri (1999) tarafından önerilen kesme noktası tekniği ile kavram ağları oluşturulmuştur. Şekil 1'de öğrencilerin periyodik tablo konusu ile ilgili kesme noktası tekniği ile oluşturulan kavram ağları belirtilmektedir. Şekil 1'deki kavram ağları, kesme noktası 25-35, 15-24, 5-14 ve 1-4 olacak şekilde, dört kesme noktası kullanılarak oluşturulmuştur. Birinci kesme noktasında (25-35), öğrencilerin sadece periyot, grup ve kütle numarası anahtar kelimelerine ilişkin yatay sıra, dikey sütun ve proton ve nötron sayısı toplamı tanımlamalarını yaptıkları görülmektedir. Bu gruptaki öğrenciler ayrıca, periyot kavramını periyodik tablo ile ilişkilendirmişlerdir. İkinci kesme noktasında (15-24) öğrenciler geçiş metalleri hariç diğer anahtar kelimelere ilişkin kavramların ortaya çıktığ görülmektedir. Öğrenciler periyodik tabloda gruplarla soy gazlar ve alkali metallerini ilişkilendirerek, yedi tane periyot olduğunu, atom numarasının proton sayısını ifade ettiğini belirtmektedir. Üçüncü kesme noktasında (5-14), öğrencilere verilen tüm anahtar kelimeler ortaya çıkmaya başlamıştır. Dördüncü kesme noktasında (1-4) ise öğrencilerin hem anahtar kelimelerle ilişkili kavram sayısı artmış, hem de anahtar kelimelerin birbiri arasındaki ilişkilerin artışı gözlenmektedir. Ayrıca, artan ilişki ve kavramlarla birlikte bazı kavram yanılgıları da dikkat çekmektedir. Örneğin, öğrenciler alüminyum ve yarı metal olan bor elementlerini geçiş metalleri ile ilişkilendirmişlerdir.

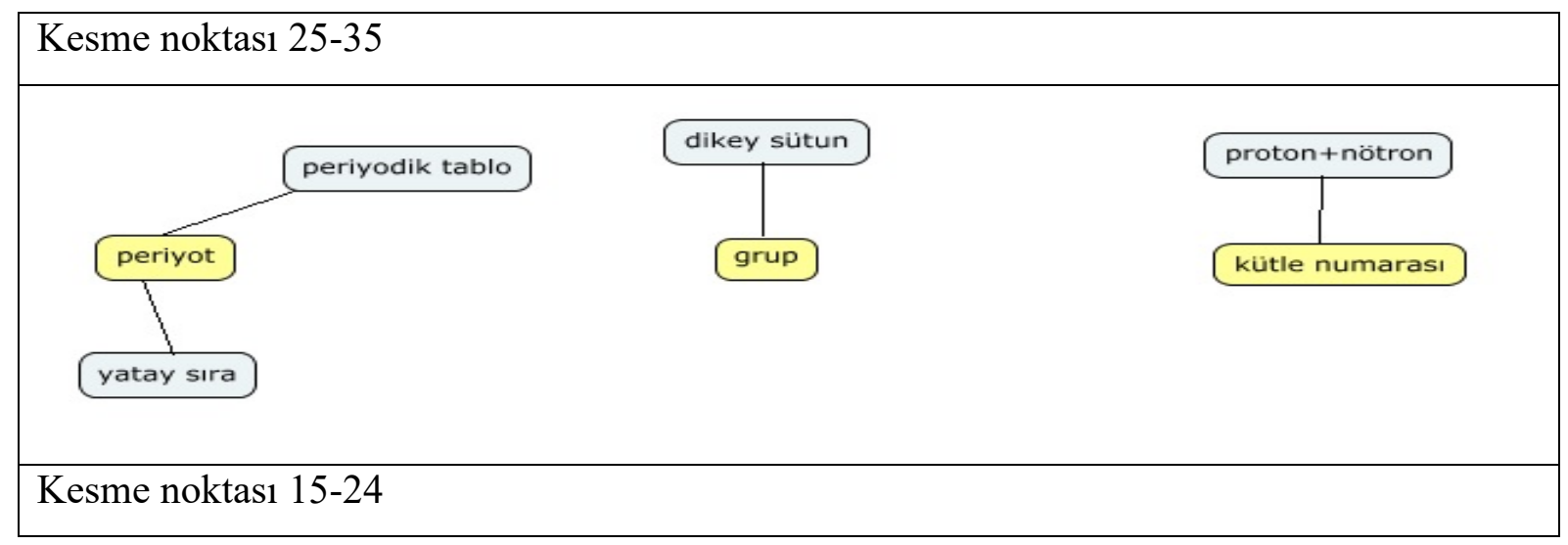


YYÜ Eğitim Fakültesi Dergisi (YYU Journal of Education Faculty), 2020; 17(1):511-533, http://efdergi.yyu.edu.tr,

doi:10.33711/yyuefd.693831

Araştırma Makalesi

ISSN: 1305-2020

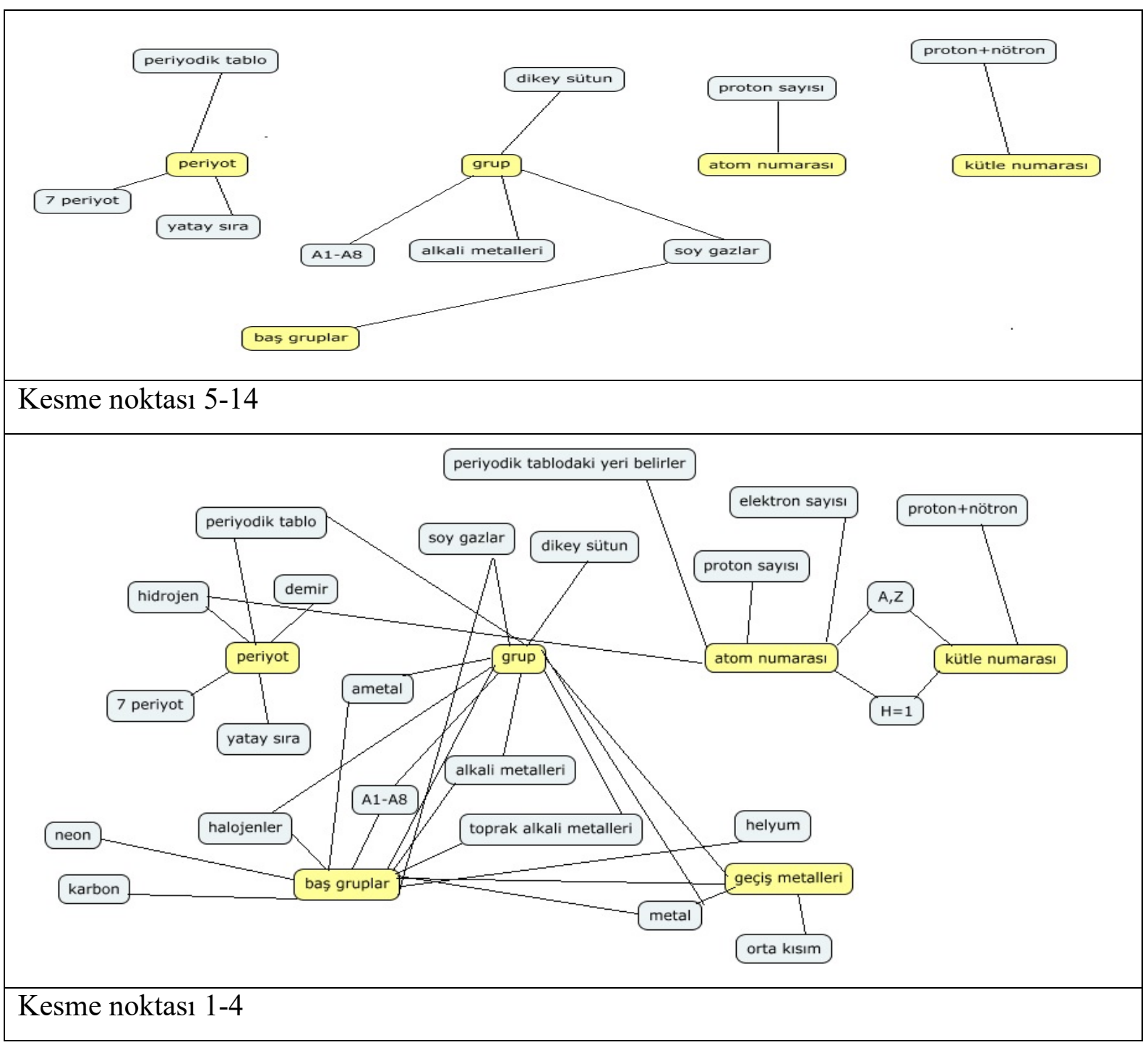




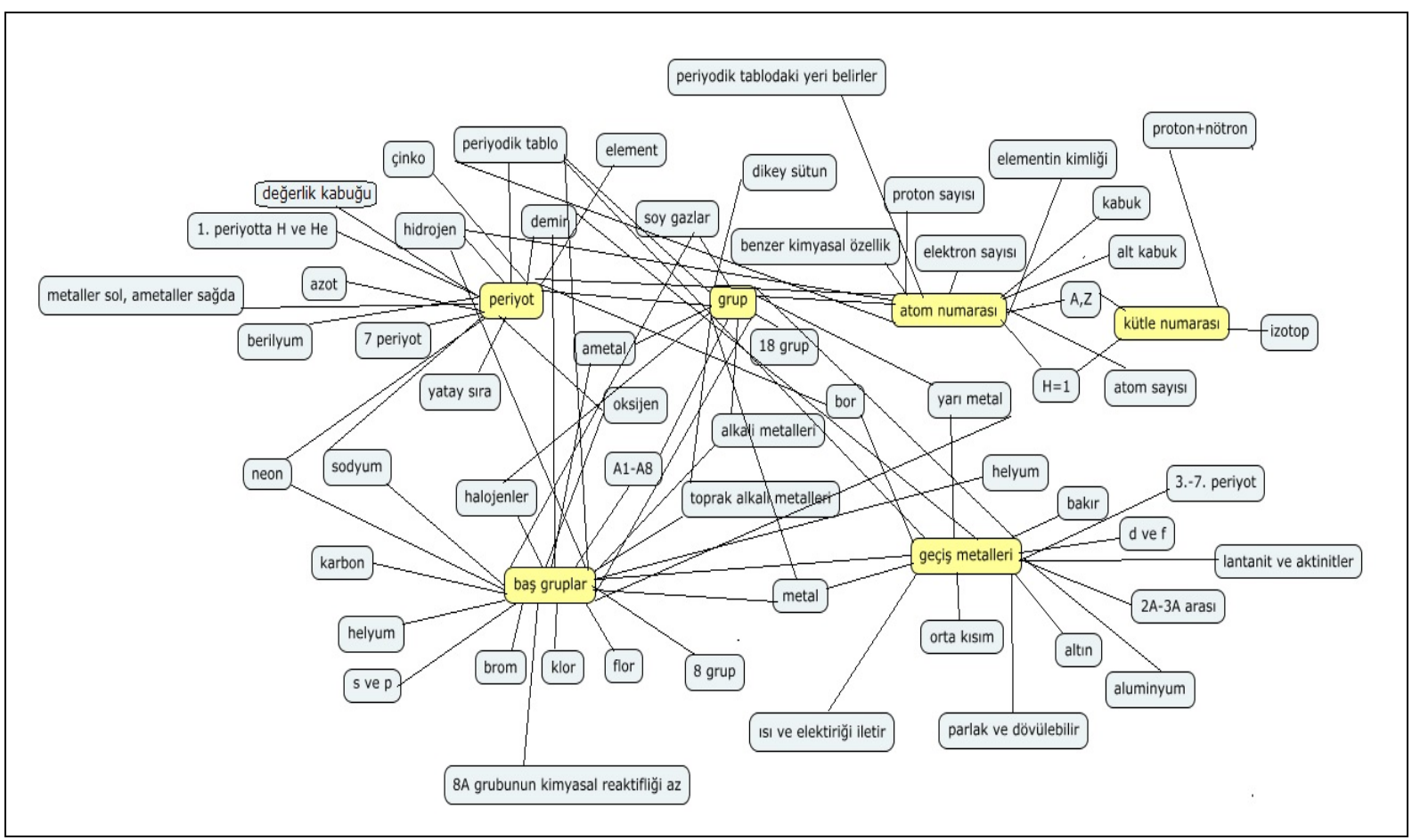

Şekil 1. Kesme Noktası Tekniği ile Elde Edilen Kavram Ağları

Şekil 1 incelendiğinde kesme noktası 25 ve yukarısı aralığındaki öğrencilerin periyot kavramı ile ilgili periyodik tablo ve yatay sıra kelimelerini yazarken, grup kavramı ile ilgili sadece dikey sütun, kütle numarası ile proton ve nötron sayısı toplamı arasında ilişki kurabildiğini ve diğer anahtar kelimelere ilişkin bağlantı yapamadıkları görülmektedir.

Kesme noktası 15-24 aralığındaki öğrencilerin, periyot, grup, atom numarası, kütle numarası ve baş grup kavramlarına ilişkin yanıtlar vermelerine karşın geçiş metalleri ile ilgili hiç yanıt vermedikleri görülmektedir. Bu aralıkta, öğrenciler grup anahtar kelimesini soygaz ve alkali metallerle ilişkilendirirken; ana grup elementleri ile sadece soygaz grubu arasında ilişki kurmaları, periyodik tabloda 7 periyot bulunduğunu belirtmeleri, atom ve kütle numaralarına ilişkin sadece proton ve proton ile nötron sayısı toplamı şeklinde açıklama yapmaları bu çalışma açısından dikkat çekicidir.

Kesme noktası 5-14 aralığında, öğrencilerin hidrojen, helyum, neon, karbon, demir gibi elementleri periyot ve baş gruplar ile ilişkilendirdikleri görülmektedir. Ayrıca öğrencilerin kütle ve atom numarasının sembolü olarak bilinen $A$ ve $Z$ harflerini yanıt olarak verdikleri, hidrojenin atom ve kütle numarasının bir olduğunu belirttikleri, atom numarasının periyodik tabloda elementlerin yerleri ile arasındaki ilişkiyi kurdukları görülmektedir. Ayrıca, bu aralıktaki öğrenciler, proton sayısının yanında elektron sayısını da atom numarası ile ilişkilendirmişlerdir. 
Kesme noktası 1-4 aralığında, öğrencilerin periyot, baş grup ve geçiş metalleri anahtar kelimelerine ilişkin daha zengin örnekler verdiği görülmektedir. Öğrenciler, geçiş metalleri ile ilgili olarak 2A ve 3A grupları arasında yer alan, 1s1 ve elektriği iletme, parlaklık ve tel haline getirebilme gibi metalik özellikleri ilişkilendirmişlerdir. Ayrıca geçiş metalleri ile lantanit ve aktinit gruplarını, d ve f orbitallerini ilişskilendirmişlerdir.

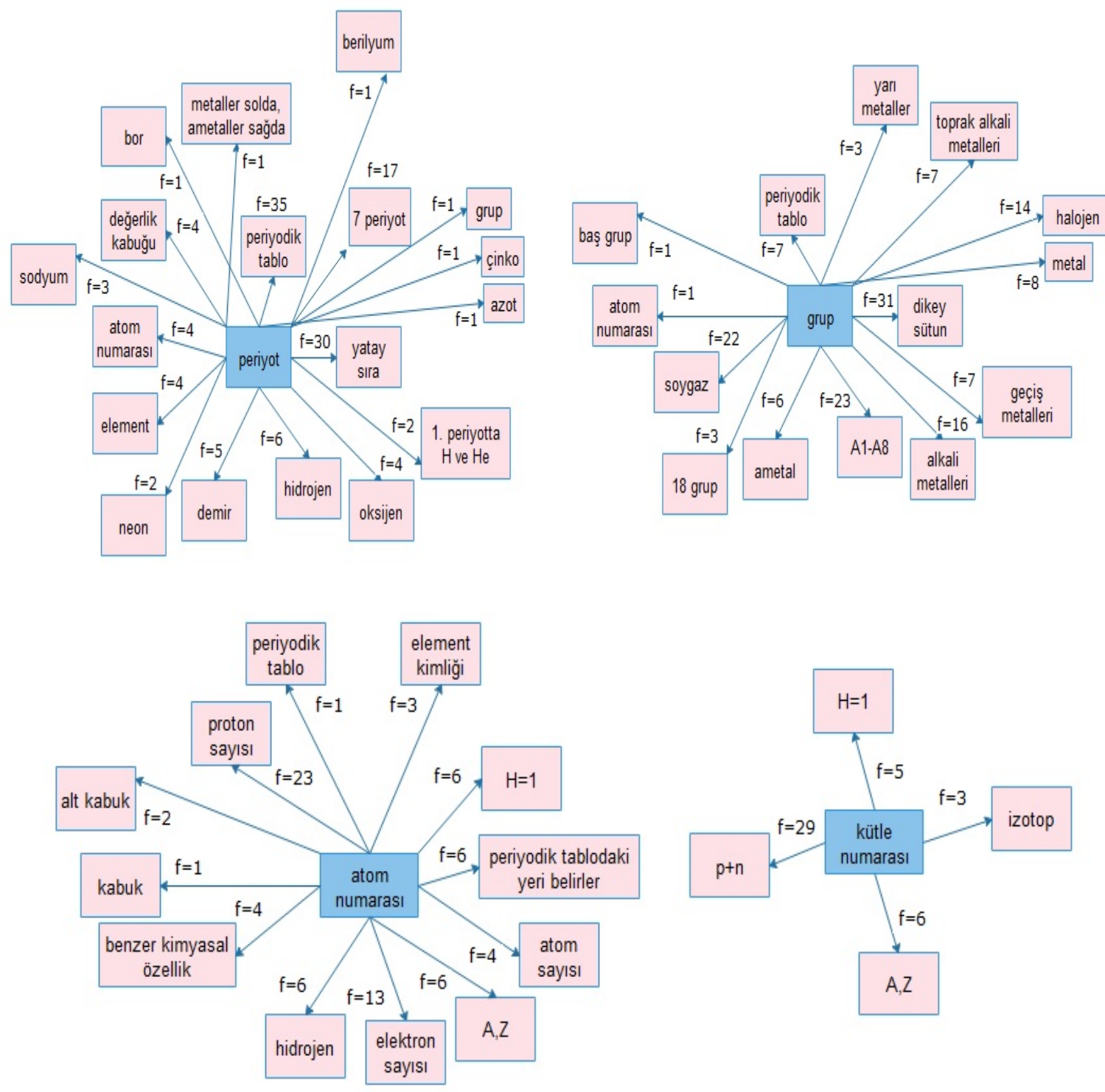



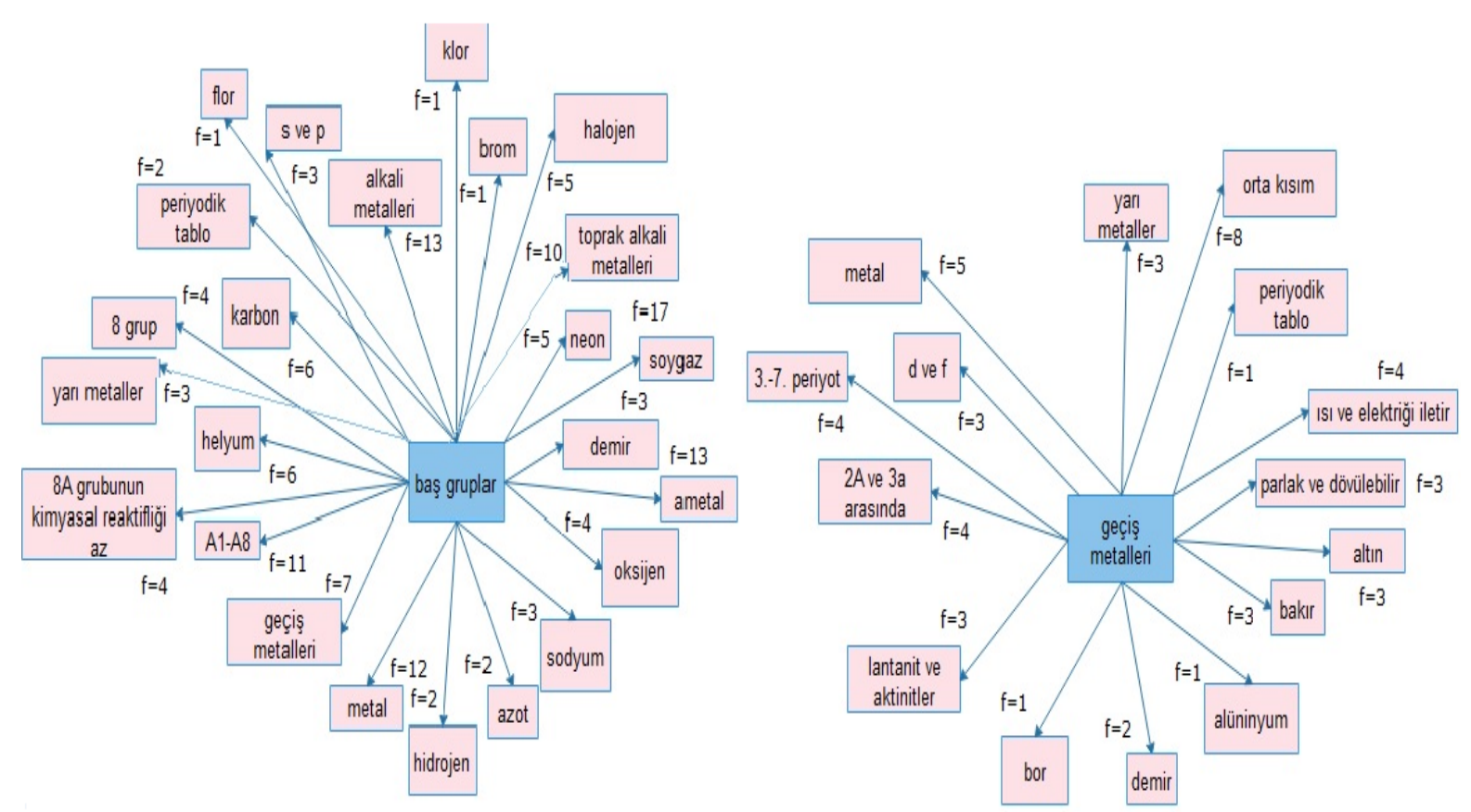

Şekil 2. Öğrencilerin Periyodik Tablo Kavramları ile İlişkili Bilişsel Yapıları

Öğrencilerin periyodik tablo konusuna ilişsin bilişsel yapılarını ortaya koymak amacıyla, ilgili anahtar kelimelere verilen yanıtların frekansları dikkate alınarak Şekil 2'deki model oluşturulmuştur. Bu şekilde öğrencilerin periyodik tablo konusuna ilişkin kavramsal yapıları ortaya çıkarılmıştır. Bu bağlamda, üniversite öğrencileri periyot anahtar kelimesine ilişkin olarak en çok periyodik tablo $(\mathrm{f}=35)$ yanıtını verirken, grup anahtar kelimesini en çok dikey sütun $(\mathrm{f}=31$ ) olarak belirtmişlerdir. Ayrıca, periyodik tabloda elementlerin konumunu ifade ederken önem taşıyan grup ve periyot anahtar kavramlarına verilen yanıtlar karşılaştırıldığında, öğrencilerin periyot anahtar kelimesine ilişkin daha çok yanıt verdikleri görülmektedir. Bunun yanında, atom numarasına en çok proton sayısı ( $\mathrm{f}=23)$, kütle numarasına ilişkin en çok proton ve nötron sayısı toplamı ( $\mathrm{f}=29)$, baş gruba en çok soygaz (17) ve geçiş metallerine ilişkin en çok orta kısım ( $\mathrm{f}=8)$ yanıtları verilmiştir. Üniversite öğrencilerinin bilişsel yapıları incelendiğinde, öğrencilerin periyodik tablodaki gruplardan en çok soygazlarla $(\mathrm{f}=22)$ ilişki kurdukları, ayrıca baş gruplardan alkali metalleri $(\mathrm{f}=16)$, halojenler $(\mathrm{f}=14)$ ve toprak alkali metalleri ( $\mathrm{f}=7$ ) ile ilişki kurdukları görülmektedir. Burada, bazı öğrencilerin ( $\mathrm{f}=7$ ) baş grup anahtar kelimesiyle geçiş metallerini ilişkilendirmesi ise yanlış anlama olarak ortaya çıkmaktadır. Bunun yanında, bir öğrencinin yarı metallerden bir tanesi olan bor elementini geçiş metalleriyle karıştırdığı da görülmektedir. Bu bulguya paralel olarak, öğrencilerin baş gruplarla ilgili daha çok yanıt üretmeleri, kavramsal yapılarının geçiş metalleri grubuna göre daha zengin 
olduğunu ifade etmektedir. Bunun yanında öğrencilerin, periyodik tablo konusu ile ilişkili olarak verilen anahtar kavramlardan sadece kütle numarası ve geçiş metalleri kavramlarını periyodik tablo ile yanıtlamadıkları görülmektedir.

\section{Tartışma ve Sonuç}

Kimya eğitiminde periyodik tablo konusu, elementleri tanımaya giriş niteliği taşıması açısından oldukça önemli bir konudur (Sarıtaş \& Tufan, 2019). Çalışmanın araştırma problemi kapsamında üniversite öğrencilerinin periyodik tablo konusu ile ilişkili bilişsel yapılarının belirlenmesinde kelime ilişkilendirme testleri kullanılmıştır. Öğrencilerin bilişsel yapılarında, periyodik tablo konusu ile ilgili hangi kavramların olduğu ve bu kavramlar arasındaki ilişkiler kelime ilişkilendirme testi aracılığı ile ortaya çıkarılmıştır. Çalışmada elde edilen bulgulara göre öğrencilerin periyodik tablo konusu ile ilgili bilişsel yapıları incelenmiştir. Kelime ilişkilendirme testlerinden elde bulgulardan yararlanarak hazırlanan Şekil 1'de, öğrencilerin periyodik tablo konusu ile ilgili kesme noktası tekniği ile oluşturulan kavram ağları gösterilmektedir. Ayrıca üniversite öğrencilerinin anahtar kelimelere verdikleri yanıtları yansıtan frekans tablosu hazırlanmıştır. Bu frekans tablosundan yararlanarak hazırlanan Şekil 2'de, üniversite öğrencilerinin periyodik tablo konusu ile ilgili bilişsel yapıları gösterilmektedir. Sonuç olarak, üniversite öğrencilerinin periyodik tablo konusu ile ilgili yeterli düzeyde bilgi sahibi olmadıkları ve bu konuya özgü kavramlarla ilgili bazı kavram yanılgılarına sahip oldukları belirlenmiştir. Tespit edilen kavramlar arası ilişkilerden yola çıkılarak bazı kavram yanılgılarının belirlenmesi, alternatif değerlendirme tekniklerinden biri olan kelime ilişkilendirme testlerinin etkili bir değerlendirme tekniği olduğunu göstermektedir.

Kesme noktası 5-14 aralığında öğrenciler, baş grupları A1-A8 olarak ifade ederek alkali metalleri, toprak alkali metalleri, halojenler ve soy gazları örnek olarak belirtmişlerdir. $\mathrm{Bu}$ aralıktaki öğrenciler, geçiş metallerinin periyodik tablonun orta kısmındaki gruplar olduğunu, metal olduklarını belirtmişlerdir. Bazı öğrencilerin geçiş metallerini baş gruplarla ilişkilendirmesi ise yanlış anlama olarak karşımıza çıkmaktadır.

Çalışma sonucunda elde edilen bilişsel yapılar incelendiğinde, sadece kesme noktası 14 aralığındaki öğrencilerin geçiş metallerini d ve f orbitalleri ile ilişkilendirmiş olmaları öğrencilerin büyük bir kısmının bu ilişkiyi kuramadığını göstermektedir. Öğrencilerin geçiş 
metallerini yarı metallerle eşleştirerek, bor elementini geçiş metali olarak örnek vermesi gibi hatalı/eksik anlamalara sahip oldukları belirlenmiştir. Ayrıca sadece kesme noktası 1-4 aralığındaki öğrencilerin, metallerin ısı ve elektrik iletkenliği ya da parlak ve dövülebilir şeklindeki genel özelliklerini belirtmiş olmaları öğrencilerin büyük bir çoğunluğunun yetersiz bilgiye sahip olduklarına işaret etmektedir. Literatür incelendiğinde Nicoll (2001), periyodik tablo ile ilgili olarak öğrencilerin kabuk ve orbital kavramlarını karıştırdıklarını belirtmiştir. Karamustafaoğlu ve Ayas (2002) tarafından yapılan bir başka çalışmada ise bütün öğretim seviyelerindeki öğrencilerin; metal, ametal ve yarımetal kavramlarıyla ilgili kavram yanılgılarına ve yanlış anlamalara sahip oldukları tespit edilmiştir.

$\mathrm{Bu}$ çalışma sonuçlarına göre öğrenciler, baş gruplara ilişkin olarak ise, s ve p orbitalleri ile ilişki kurmuşlar ve $8 \mathrm{~A}$ grubu elementlerinin kimyasal reaktifliklerinin az olduklarını belirtmişlerdir. Periyot anahtar kavramına ilişkin, metallerin periyodik tablonun sol, ametallerin sağ kısmında bulundukları, periyot sayısı ile değerlik kabuğu arasında bağlantı kurdukları söylenebilir. Bu aralıkta yer alan öğrencilerin, kütle numarası ile izotop kavramı arasında, atom numarası ile periyodik tablodaki yer ve kimyasal özellikle ilişki kurdukları görülmektedir. Schmidt ve diğerleri (2003) öğrencilerin izotop ve allotrop gibi kavramları periyodik tablo ile ilişkilendirirken güçlük yaşadıklarını belirtmektedir. Yine bu çalışma sonunda bazı öğrencilerin atom numarasını atom sayısı ile karıştırdıkları da görülmektedir. Ayrıca, bu aralıktaki öğrenciler; proton sayısının yanı sıra elektron sayısını da atom numarası ile ilişkilendirmişlerdir. Schmidt ve diğerleri (2003), bir atomun elektron sayısının belirtilmesinde, elektron sayısının atom için doğru iyon için yanlış olabileceğini belirtmektedir.

Eğitimciler, kelime ilişkilendirme testlerini, birer tanıma ve yerleştirmeye yönelik değerlendirme aracı olarak kullanabilirler. Bu tür bir değerlendirme, öğrencilerin önkoşul niteliğindeki davranışlara ne kadar sahip olup olmadığını belirleme de yardımcı olacaktır. Böylece eğitimciler öğretimi öğrencilerinin düzeyine göre düzenleyebileceklerdir. Belki sınıf içerisinde işbirliğine dayalı öğrenme için oluşturulacak olan gruplar, kelime ilişkilendirme testleri puanlarından elde edilen puanlara göre yapılabilir. Kelime ilişkilendirme testleri, aynı zamanda bir ünite veya konudaki öğrencilerin sahip oldukları öğrenme eksikliklerini ve güçlüklerini belirlemede de kullanılabilir. Bu şekilde öğrencinin eksik olan bilişsel yapılarından yola çıkılarak her öğrenciye farklı desteklerde bulunabilir. Son olarak kelime ilişkilendirme testleri istenildiğinde düzey belirlemeye yönelik değerlendirme amaciyla yani öğrencilere not vermek gibi bir amaçla da kullanılabilir. Çünkü kelime ilişkilendirme testlerinin 
hazırlanmasının ve değerlendirilmesinin nispeten kolay olması eğitimcilere kolaylık sağlayacaktır.

\section{Öneriler}

Yapılan bu çalışma ile üniversite öğrencilerinin periyodik tablo konusuna ilişkin bilişsel yapıları kelime ilişkilendirme testleri kullanılarak belirlenmeye çalışılmıştır. Çalışma sonunda, üniversite öğrencilerinin, kimyanın temel konularından biri olan periyodik tablo konusuna ilişkin olarak istenilen düzeyde bilgi sahibi olmadıkları tespit edilmiştir. Öğrencilerin bazılarının, atom numarası ile atom sayısını, geçiş metalleri ile yarı-metalleri, kabuk ve orbital kavramlarını karıştırdıkları saptanmıştır. Kelime ilişkilendirme testleri, hedef öğrenmelerin gerçekleşip gerçekleşmediğini belirlemek amacıyla, öğrencilerin bilişsel yapılarını ortaya çıkartılmasında kullanılabilecek pratik bir değerlendirme tekniğidir. Kelime ilişkilendirme testlerinin, fen eğitimi alanında yapılacak olan ileriki çalışmalarda özellikle öğrencilerin kavramsal anlamalarını değerlendirmede kullanılması önerilmektedir. Bunun yanında, kimyanın birçok kavramı ile ilişkili olan periyodik tablo konusu öğretim basamağında kelime ilişkilendirme testlerinin hem teşhis hem tanı aracı hem de hedef öğrenmelerin ne düzeyde gerçekleşip gerçekleşmediğini tespit etmek için kullanılması önerilmektedir.

\section{Makalenin Bilimdeki Konumu}

Matematik ve Fen Bilimleri Eğitimi Bölümü/Kimya Eğitimi

\section{Makalenin Bilimdeki Özgünlüğü}

Çağdaş eğitimin öngördüğü eğitim ortamlarında alternatif değerlendirme tekniklerinin kullanılması önem taşımaktadır. Çalışmada, alanyazında bilişsel yapıların belirlenmesinde yaygın bir kullanımı olan kelime ilişkilendirme testlerinin üniversite öğrencilerinin periyodik tablo konusu ile ilgili bilişsel yapılarının ortaya çıkarılmasında kullanılması incelenmiştir. Kimyanın konularına temel oluşturan Periyodik Tablo konusunda öğrencilerin bilişsel yapılarının incelenmesi kimya eğitimi açısından önemlidir. Bu açıdan bakıldığında, yapılan çalışmanın alanyazına özgün ve anlamlı bir değer kattığı düşünülmektedir. 


\section{Kaynaklar}

Abraham, M. R., Williamson, V. M., \& Westbrook, S. L. (1994). A cross-age study of the understanding of five chemistry concepts. Journal of Research in Science Teaching, $31(2), 147-165$.

Aydın, A. (2008). Ortaöğretim kimya dersi öğretim programında periyodik sistem ile ilgili kavramların verilişs sırasının incelenmesi (ABD ve Türkiye örneği). Balıkesir Üniversitesi Fen Bilimleri Enstitüsü Dergisi, 10(1), 76-84.

Azizoğlu, N., Aslan, S., \& Pekcan, S. (2015). The periodic system and teaching with analogies model: The effects of teaching method, gender and motivation on students' achievement. Elementary Education Online, 14(2), 472-488.

Bahar, M., \& Özatlı, N. S. (2003). Kelime iletişim test yöntemi ile lise 1. sınıf öğrencilerinin canlıların temel bileşenleri konusundaki bilişsel yapılarının araştırılması. Balıkesir Üniversitesi Fen Bilimleri Enstitüsü Dergisi, 5(2), 75-85.

Bahar, M. (2003). Misconceptions in biology education and conceptual change strategies. Educational Sciences: Theory \& Practice, 3(1), 55-64.

Bahar, M., Johnstone, A.H. \& Sutcliffe, R.G. (1999). Investigation of students' cognitive structure in elementary genetics through word association tests. Journal of Biological Education, 33, 134-141.

Balbağ, M. Z. (2018). Fen bilgisi öğretmen adaylarının hız ve sürat kavramlarına ilişkin bilişsel yapıları: Kelime İlişkilendirme Testi (KİT) uygulaması. Dicle Üniversitesi Ziya Gökalp Eğitim Fakültesi Dergisi, 33, 38-47.

Barak, M., \& Dori, Y. J. (2005). Enhancing undergraduate students' chemistry understanding through project-based learning in an IT environment. Science Education, 89(1), 117-139. 
Bayir, E. (2014). Developing and playing chemistry games to learn about elements, compounds, and the periodic table: Elemental Periodica, Compoundica, and Groupica. Journal of Chemical Education, 91(4), 531-535.

Ben-Zvi, N., \& Genut, S. (1998). Uses and limitations of scientific models: the Periodic Table as an inductive tool. International Journal of Science Education, 20(3), 351-360.

Bilgin, İ., Aktaş, İ., Tatar, E., \& Tüysüz, C. (2016). Rehberli araştırma yönteminin üniversite öğrencilerinin kimya konularındaki bazı kavramları anlamalarına etkisinin incelenmesi. Türkiye Kimya Derneği Dergisi, Kısım C: Kimya Eğitimi, 1(1), 129-146.

Bradley, J. D., \& Mosimege, M. D. (1998). Misconceptions in acids and bases: A comparative study of student teachers with different chemistry backgrounds. South African Journal of Chemistry, 51, 137-145.

Burrows, N. L., \& Mooring, S. R. (2015). Using concept mapping to uncover students' knowledge structures of chemical bonding concepts. Chemistry Education Research and Practice, 16(1), 53-66.

Cachapuz, A. F. C. \& Maskill, R. (1987). Detecting changes with learning in the organization of knowledge: Use of word association tests to follow the learning of collision theory. International Journal of Science Education, 9(4), 491-504.

Carson, E. M., \& Watson, J. R. (2002). Undergraduate students' understandings of entropy and Gibbs free energy. University Chemistry Education, 6(1), 4-12.

Çelikkaya, T., \& Kürümlüoğlu, M. (2019). Sosyal bilgiler dersi "Demokrasinin Serüveni” ünitesi ile öğrencilerin bilişsel yapılarının ve kavramsal gelişim süreçlerinin incelenmesi. Anadolu Üniversitesi Eğitim Bilimleri Enstitüsü Dergisi, 9(1), 56-86.

Demircioğlu, H., Demircioğlu, G., \& Çalik, M. (2009). Investigating the effectiveness of storylines embedded within a context-based approach: the case for the Periodic Table. Chemistry Education Research and Practice, 10(3), 241-249. 
Ercan, F., Taşdere, A., \& Ercan, N. (2010). Observation of cognitive structure and conceptual changes through word associations tests. Journal of Turkish Science Education, 7(2), 136154.

Franco-Mariscal, A. J., Oliva-Martínez, J. M., \& Almoraima Gil, M. L. (2014). Students' perceptions about the use of educational games as a tool for teaching the periodic table of elements at the high school level. Journal of Chemical Education, 92(2), 278-285.

Geçgel, G., \& Şekerci, A. R. (2018). Bazı kimya konularındaki alternatif kavramların tanılayıcı dallanmış ağaç tekniği kullanarak belirlenmesi. Mersin Üniversitesi Eğitim Fakültesi Dergisi, 14(1), 1-18.

Gunstone, R. F. (1980). Word association and the description of cognitive structure. Research in Science Education, 10(1), 45-53.

Hastürk, H. G. (2017). Fen öğretiminde alternatif ölçme-değerlendirme teknikleri. H. Gamze Hastürk (Ed.), Teoriden pratiğe fen bilimleri öğretimi içinde (s. 522-524). Ankara: Pegem Akademi.

Hovardas, T., \& Korfiatis, K. J. (2006). Word associations as a tool for assessing conceptual change in science education. Learning and Instruction, 16(5), 416-432.

Işıklı, M., Taşdere, A., \& Göz, N. L. (2011). Kelime ilişkilendirme testi aracılığıyla öğretmen adaylarının Atatürk ilkelerine yönelik bilişsel yapılarının incelenmesi. Uşak Üniversitesi Sosyal Bilimler Dergisi, 4(1), 50-72.

Jenkins, J. L., \& Shoopman, B. T. (2019). Identifying misconceptions that limit student understanding of molecular orbital diagrams. Science Education International, 30(3), 152-157.

Johnstone, A. H., \& Moynihan, T. F. (1985). The relationship between performances in word association tests and achievement in chemistry. The European Journal of Science Education, 7(1), 57-66. 
Jonassen, D. H. (1987). Assessing cognitive structure: Verifying a method using pattern notes. Journal of Research \& Development in Education, 20(3), 1-14.

Karamustafaoğlu, S., \& Ayas, A. (2002). Farklı öğrenim seviyelerindeki öğrencilerin "metal, ametal, yarımetal ve alaşım" kavramlarını anlama düzeyleri ve kavram yanılgıları. M. Atatürk Eğitim Fakültesi Eğitim Bilimleri Dergisi, 15,151-162.

Karslı, F., \& Ayas, A. (2017). Fen bilimleri öğretmen adaylarının kavramsal değişimlerine zenginleştirilmiş laboratuvar rehber materyalinin etkisi: buharlaşma ve kaynama. Yüzüncü Yıl Üniversitesi Eğitim Fakültesi Dergisi, 14(1), 529-561.

Nakhleh, M. B. (1992). Why some students don't learn chemistry: Chemical misconceptions. Journal of Chemical Education, 69(3), 191-196.

Nakiboglu, C. (2008). Using word associations for assessing non-major science students' knowledge structure before and after general chemistry instruction: the case of atomic structure. Chemistry Education Research and Practice, 9(4), 309-322.

Nicoll, G. (2001). A report of undergraduates' bonding misconceptions. International Journal of Science Education, 23(7), 707-730.

Özmen, H. (2004). Some student misconceptions in chemistry: A literature review of chemical bonding. Journal of Science Education and Technology, 13(2), 147-159.

Patton, M. Q. (1990). Qualitative evaluation and research methods. SAGE Publications, inc.

Pikoli, M. (2020). Using Guided Inquiry Learning with Multiple Representations to Reduce Misconceptions of Chemistry Teacher Candidates on Acid-Base Concept. International Journal of Active Learning, 5(1), 1-10.

Sadoglu, G. P., \& Durukan, U. G. (2018). Determination of elementary prospective teachers’ perceptions of some basic physics concepts by word association test. European Journal of Physics Education, 8(2), 44-57. 
Sarıtaş, D., \& Tufan, Y. (2019). Periyodik yasa-sistem ilişkisi nasıl kurulmalıdır? Kimya öğretimine bilim tarihi ve felsefesinden çıkarımlar. Hacettepe Üniversitesi Eğitim Fakültesi Dergisi, 34(1), 27-53. doi: 10.16986/HUJE.2018043649

Schmidt, H. J., Baumgärtner, T., \& Eybe, H. (2003). Changing ideas about the periodic table of elements and students' alternative concepts of isotopes and allotropes. Journal of Research in Science Teaching: The Official Journal of the National Association for Research in Science Teaching, 40(3), 257-277.

Shavelson, R. J. (1972). Some aspects of the correspondence between content structure and cognitive structure in physics instruction. Journal of Educational Psychology, 63(3), 225234.

Shavelson, R. J. (1973). What is the basic teaching skill?. Journal of Teacher Education, 24(2), 144-151.

Shavelson, R. J. (1974). Methods for examining representations of a subject-matter structure in a student's memory. Journal of Research in Science Teaching, 11(3), 231-249.

Stavy, R. (1991). Using analogy to overcome misconceptions about conservation of matter. Journal of Research in Science Teaching, 28(4), 305-313.

Şen, Ş., Varoğlu, L., \& Y1lmaz, A. (2019a). Examination of undergraduates' cognitive structures on reaction rates and chemical equilibrium. Pamukkale University Journal of Education, 45(45), 335-352.

Şen, Ş., Varoğlu, L., \& Yılmaz, A. (2019b). Cognitive structures and misconceptions with a thematic framework: The case of chemical bonding. Journal of Education and Future, $16,65-78$.

Tsai, C. C., \& Huang, C. M. (2002). Exploring students' cognitive structures in learning science: a review of relevant methods. Journal of Biological Education, 36(4), 163-169.

Yıldırım, A., \& Şimşek, H. (2011). Sosyal bilimlerde nitel araştırma yöntemleri (8. Baskı). Ankara: Seçkin Yayıncılık. 
Yücel, E. Ö., \& Özkan, M. (2015). Determination of secondary school students' cognitive structure, and misconception in ecological concepts through word association test. Educational Research and Reviews, 10(5), 660-674. 


\section{Summary}

\section{Statement of Problem}

Because of the abstract properties of chemistry concepts, students have problems in learning and understanding chemistry concepts. This is because in order to understand complex chemistry topics involving many abstract concepts, students need to develop consistent knowledge structures and understand interrelated concepts (Burrows \& Mooring, 2015). The periodic table is a model that makes an important contribution to the chemistry and reflects information about the location, structure and properties of the elements (Ben-Zvi \& Genut, 1998). Although the periodic table can be drawn and seen, most of the information expressed is abstract (Azizoğlu, Aslan \& Pekcan, 2015). The periodic table is important for chemistry educators as it provides the basis for chemistry subjects.

Cognitive structure is the theoretical structure representing the conceptual relationships in the long-term memory of students (Shavelson, 1974). In the teaching process, examining the cognitive structures of the students will contribute to the learning outcomes thus will be effective in the development of teaching strategies (Tsai \& Huang, 2002).

In learning process, analyzing the cognitive structures in order to reveal how the information is structured by the individuals will provide various information for the researchers. For this purpose, one of the techniques that frequently used in revealing cognitive structures in the literature is word association test.

\section{Purpose of the Study}

The aim of the study is to investigate the cognitive structures of undergraduate students related to the periodic table by the word association test.

\section{Research Problem}

How are the cognitive structures of students about the periodic table that reveal with word association test?

\section{Method}

The case study that is one of the qualitative research methods was utilized in the study. A total of 123 undergraduate students who attend General Chemistry course at the engineering faculty of a foundation university in the spring term of 2018-2019 participated. In order to determine the cognitive structures of the students about the periodic table, which is one of the subjects of general chemistry, the data were collected after the teaching was processed by the 
lecturer. All participants participated in the study voluntarily. In furtherance to reveal the cognitive structures of the students, the word association test consisted of period, group, atomic number, mass number, main group and transition metal stimulus words were used. The data were analyzed through content analysis. The frequency table was prepared by evaluating the responses of each keyword in the word association test and the cognitive structures were examined by using the cut-off technique.

\section{Findings and Discussion}

Figure 1, reflects the concept networks created by the cut-off technique related to the periodic table of undergraduate students. In order to reveal the cognitive structures of the students on the subject of periodic table, considering the frequencies of the responses given to the related stimulus words, the model in Figure 2 was formed. In this way, the conceptual structures of the students about the periodic table have been revealed.

In the range of cut-off point 25 and up, it revealed that while the students can establish periodic table and horizontal row words related to the period concept, they only appoint vertical column with group concept and the total number of protons and neutrons with mass number. In addition, students cannot link any word to other keywords.

In the range of cut-off point 15-24, students respond to the concepts of period, group, atomic number, mass number and main group, in contrast with transition metal concept.

In the range of cut-off point 5-14, it examined that students associate elements such as hydrogen, helium, neon, carbon, iron with period and main group concepts. In addition, students answered with the letters $\mathrm{A}$ and $\mathrm{Z}$, which are known as the symbol of mass and atomic number, they indicated hydrogen has atomic number and mass number as a one, and revealed the relationship between atomic number and elements' location in the periodic table.

In the range of cut-off point 1-4, students have given advanced examples about period, main group and transition metal stimulus words. It was determined that the students have misconceptions because of they linked transition metals with the semi-metals, stated boron as a transition metal.

\section{Conclusions and Recommendations}

In this study, the cognitive structures of the undergraduate students about the periodic table were revealed and concluded by using word association test. As a result, it revealed that undergraduate students do not have the desired level of knowledge about the periodic table subject, which is one of the basic subjects for chemistry. It found that some of the students had 
confusion about the atomic number and the number of atoms; transition metals and semi-metals; shell and orbital concepts. The word association tests are a practical evaluation technique that can be used to reveal cognitive structures of students in order to determine whether or not the target learning has accrued. It is suggested that word association tests could be used to evaluate the conceptual understanding of students, especially in future studies in the field of science education. 